\title{
Semantic Web-Based Supplier Discovery Framework
}

\author{
Jaehun Lee ${ }^{1}$, Kiwook Jung ${ }^{1}$, Bo Hyun Kim², and Hyunbo Cho ${ }^{1}$ \\ ${ }^{1}$ Pohang University of Science \& Technology, Pohang, Gyeongbuk, South Korea \\ \{jaehun_lee, kiwook, hcho\} @postech.ac.kr \\ ${ }^{2}$ Korea Institute of Industrial Technology, Ansan, Gyeonggi, South Korea \\ bhkimakitech.re.kr
}

\begin{abstract}
As companies move forward to source globally, supply chain management has gained attention more than ever before. In particular, the discovery and selection of capable suppliers has become a prerequisite for a global supply chain operation. Manufacturing e-marketplaces have helped companies discover new suppliers and/or buyers fast and effective for their products and services. Due to the description of requirements and capabilities in isolation, their true meanings may not be uniformly interpreted from each other. The issue of semantics between suppliers and buyers, then, remains an obstacle.

The main objective is to propose a semantic web-based supplier discovery framework for building a long-term strategic supply chain. Specifically, 1) a collaboration ontology is developed to represent the supplier's capability information and the buyer's requirements. 2) Supplier's potential capability is reasoned. 3) Buyer's requirements are semantically matched with supplier's capability information. In addition, a prototype demonstrates the practicality of the framework.
\end{abstract}

Keywords: Supplier Discovery, Supply Chain Building, Semantic Web.

\section{Introduction}

Rapid globalization of business across emerging markets has changed business competition from a 'company versus company' model into a 'supply chain versus supply chain' model. A supply chain is defined as a network of participants who procure materials, develop products, and deliver them to customers according to coordinated plans [1]. As companies move forward to source globally, supply chain management has gained attention more than ever before. In particular, the discovery and selection of capable suppliers has become a prerequisite for a global supply chain operation. Conventional supplier discovery practices, such as visiting expos, making phone calls, may not contribute to search for new suppliers located overseas.

Manufacturing e-marketplaces have helped companies discover new suppliers and/or buyers fast and effective for their products and services of interest. A few examples include Alibaba.com, mfg.com, and ec21.com. Fig. 1 shows a supplier discovery scenario in e-marketplace, where a buyer attempts to find global suppliers capable of manufacturing a car front bumper mold. Due to the description 
of requirements and capabilities in isolation, their true meanings may not be uniformly interpreted from each other. The issue of semantics between suppliers and buyers, then, remains an obstacle.

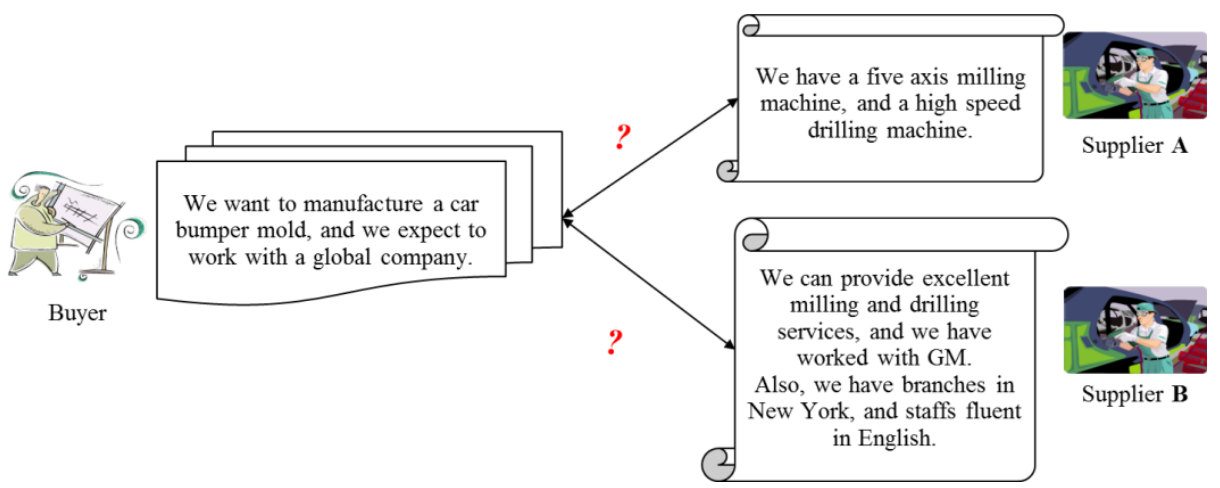

Fig. 1. Supplier discovery scenario

In response to this problem, the main objective of this paper is to propose a semantic web-based supplier discovery framework for building a long-term strategic supply chain.

\section{Semantic-Web Based Supplier Discovery Framework}

\subsection{Dimensions of Buyer's Requirements and Supplier's Capability Information}

Buyer's requirements consist of product requirements (that is, 'what to manufacture?'), and supplier requirements (that is, 'whom to manufacture with?'). On the other hand, supplier's capability comprises manufacturing capability and nonmanufacturing capability. The sub-requirements will be matched with the subcapabilities, when a buyer searches for suppliers of interest.

Matching buyer's requirements with supplier's capability requires semantic searches, because (1) buyer's requirements are not explicitly described, (2) suppliers use heterogeneous formats and terminologies in their capability description, and (3) buyers and suppliers use different level of details in describing their wishes. Therefore, the buyers may not well interpret suppliers' capabilities, and the suppliers may not recognize what the buyers want, either.

A literature survey shows that most discovery methods use product requirements only to match with the supplier's manufacturing capability at a semantic level [2-5]. These methods are not appropriate for building a long-term strategic supply chain, but for a single trading of specific products [6]. 


\subsection{Overall Supplier Discovery Framework}

A key ontology is developed to represent the supplier's capability information and the buyer's requirements. The framework includes ontology building, reasoning and semantic matching. Its brief diagram is shown in Fig. 2.

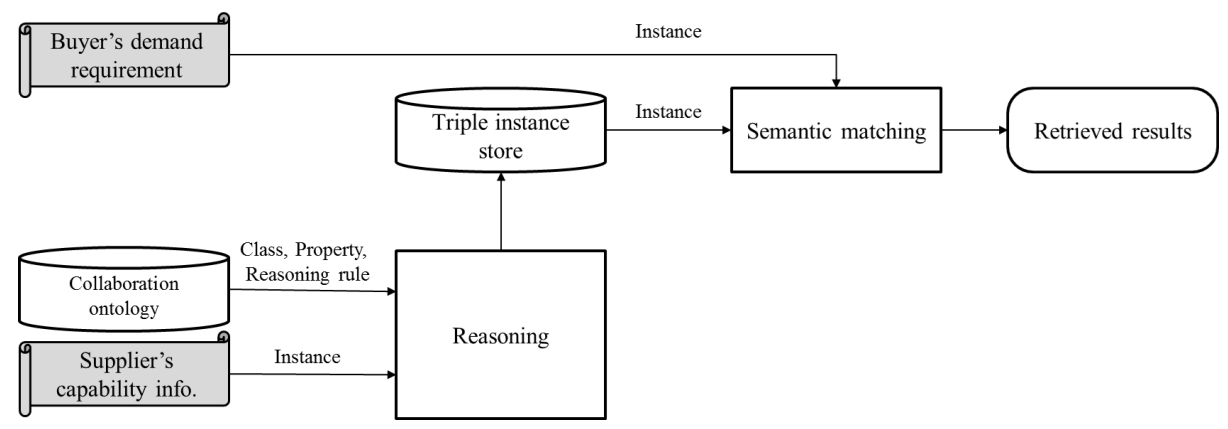

Fig. 2. Semantic-web based supplier discovery framework

1. A collaboration ontology is pre-built in order to be used for reasoning. This ontology is built in the form of Web Ontology Language (OWL), and OWL Rules Language (ORL).

2. Supplier's potential capability is reasoned from classes, properties, reasoning rules, and instances. OWL includes classes and properties, ORL is used for rules, and Resource Description Framework (RDF) for instances. Reasoning tool automates the reasoning process, and it stores the ontology model and its reasoned instances in the 'triple instance store'.

3. Finally, the buyer's requirement is semantically matched with supplier's capability information using query language.

\section{$3 \quad$ Building a Collaboration Ontology}

\subsection{An Ontology for Supplier's Capability Information}

Since the quality of the semantic search is directly determined by the richness of the representation, an ontology plays an essential part in this framework. The collaboration ontology is built using the formal representation language OWL, the most expressive semantic markup language [7]. Each ontology concept is represented as a class, using owl:Class. An OWL class is characterized by relationship-type properties using owl:ObjectProperty, or by data-type properties using owl:DatatypeProperty.

Fig. 3 shows a supplier ontology in which classes represent supplier's capability information consisting of manufacturing capability and non-manufacturing capability. For example, tool, process, part and product classes are used for reasoning regarding manufacturing capability, while patent, location, and customer classes are used for reasoning regarding non-manufacturing capability [8-9]. 


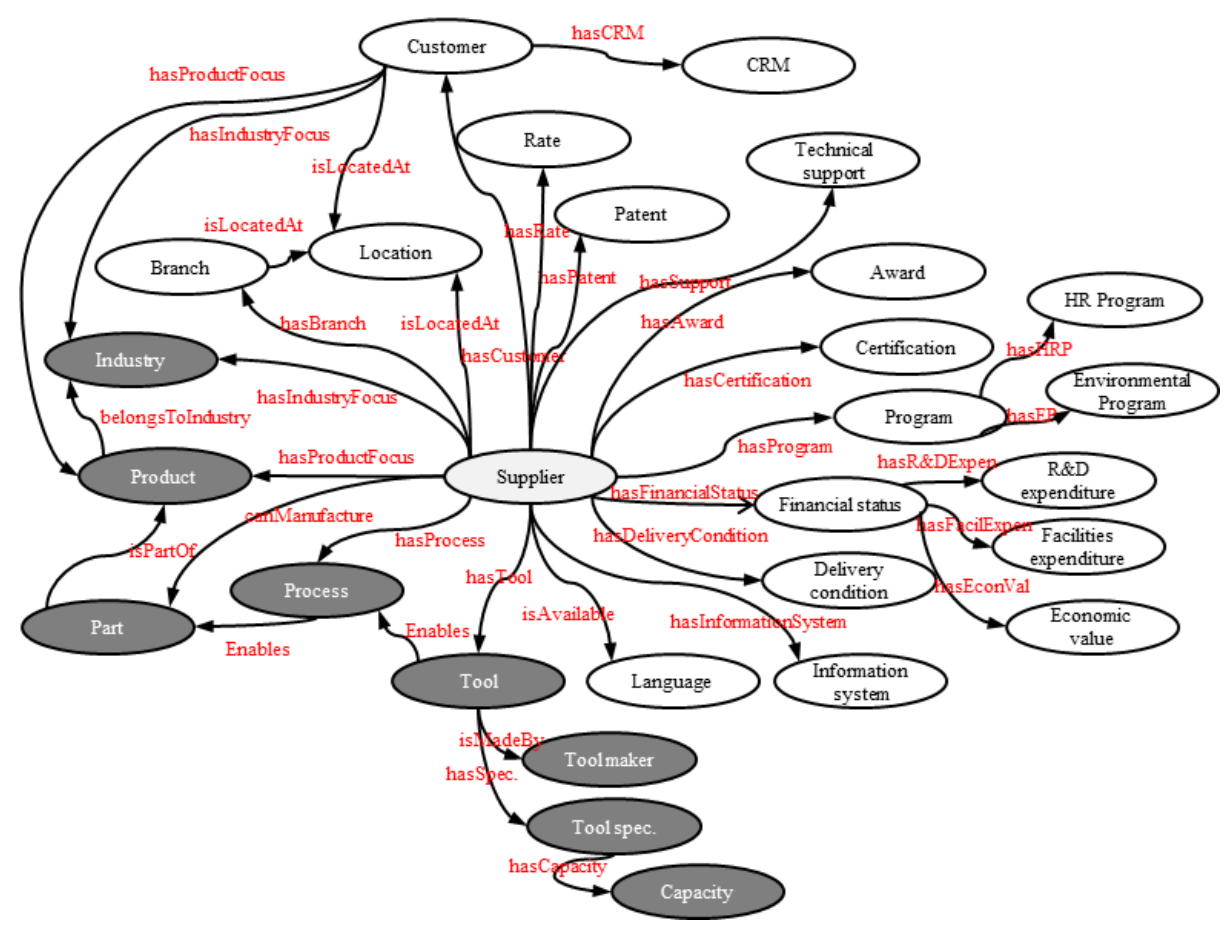

Fig. 3. Concept diagram of supplier ontology in a collaboration ontology

\subsection{An Ontology for Buyer's Requirement}

Fig. 4 shows a buyer ontology in which classes represent buyer's requirements consisting of product requirement and supplier requirement. For example, process, part, and product classes are used for reasoning regarding product requirements, while supplier requirement classes are used for reasoning regarding supplier requirements.

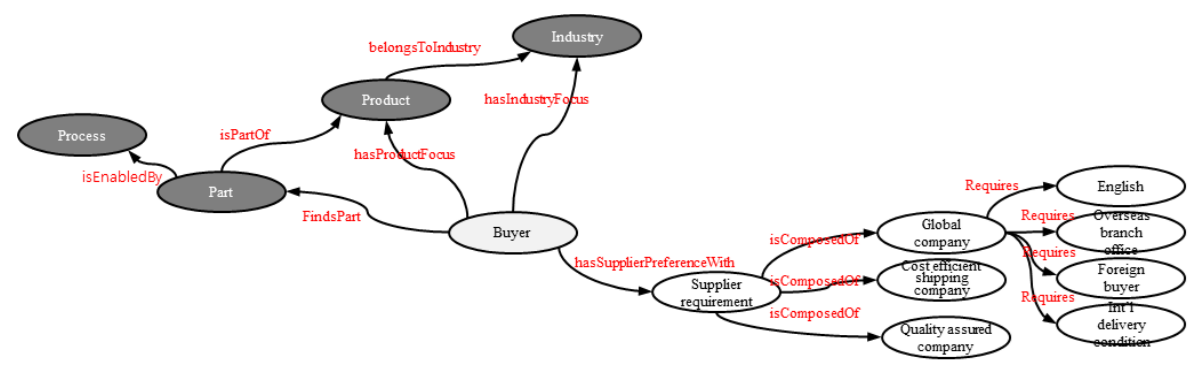

Fig. 4. Concept diagram of buyer ontology in a collaboration ontology 
Table 1 describes explicit meanings for exemplary supplier requirements.

Table 1. Explicit meanings of supplier requirements

\begin{tabular}{|l|l|}
\hline \multicolumn{1}{|c|}{ Supplier requirements } & \multicolumn{1}{c|}{ Explicit meanings } \\
\hline A global company & $\begin{array}{l}\text { A supplier can be interacted in English, has over- } \\
\text { seas branch offices, has transaction experiences with } \\
\text { foreign buyers, and can deliver products abroad }\end{array}$ \\
\hline $\begin{array}{l}\text { A company with delivery } \\
\text { competitiveness }\end{array}$ & $\begin{array}{l}\text { A supplier is located close to airport/port, has } \\
\text { various delivery conditions, and has achieved high } \\
\text { delivery performance }\end{array}$ \\
\hline $\begin{array}{l}\text { A company that provides } \\
\text { assured quality }\end{array}$ & $\begin{array}{l}\text { A supplier has high market share, has transaction } \\
\text { experiences with principal customers, has received } \\
\text { certifications by principal customers, has received } \\
\text { quality awards }\end{array}$ \\
\hline
\end{tabular}

\section{Reasoning Supplier's Potential Capability}

Suppliers may not be fully aware of the buyer's requirements that they can potentially satisfy. Therefore, reasoning supplier's potential capability based on the input data is essential. In this framework, the 'triple instance store' is used to retain reasoned supplier's potential capability and input data.

Fig. 5 presents an exemplary concept diagram about how to reason manufacturing capabilities with the supplier ontology. A car bumper mold is manufactured by milling and drilling. In addition, milling is made possible if a supplier has a milling machine, and drilling is made possible if a supplier has a high speed drilling machine and a high pressure coolant system. Thus, we can reason a supplier can manufacture a bumper mold and also provide milling and drilling process, if a supplier has a milling machine, a high speed drilling machine, and a high pressure coolant system.

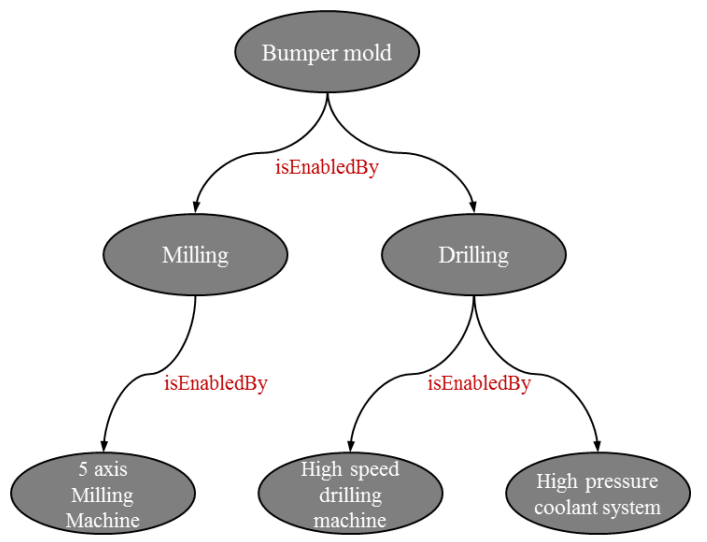

Fig. 5. Concept diagram for reasoning manufacturing capability 
In addition, the following code presents an exemplary rule about how to reason non-manufacturing capabilities with the supplier ontology. If the location of supplier is different from that of supplier's customer, supplier's customer is verified to be a foreign buyer.

\section{( ?c isa Supplier) ( ?c hascustomer ?r ) (c?isLocatedAt ?p1) ( ?r isLocatedAt ?p2) (?p1 issame ?p2) -> (?r isforeignBuyer true^^boolean)}

\section{$5 \quad$ Semantic Matching of Buyer's Requirements with Supplier's Capability Information}

Semantic matching of buyer's requirements with supplier's capability information is required to solve the issue of buyers and suppliers using different level of details in their descriptions. In this framework, (1) the buyer's product requirements and the supplier's manufacturing capability, and (2) the buyer's supplier requirement and the supplier's non-manufacturing capability are semantically matched.

Fig. 6 presents an exemplary concept diagram about how to match buyer's product requirements with supplier's manufacturing capability information. First, all the manufacturing capabilities of the supplier, such as bumper mold, are reasoned via the described processes. Subsequently, buyer's product requirements are matched with the supplier's manufacturing capability. In this framework, the bumper mold instance in the buyer ontology is matched with the front bumper mold instance in the supplier ontology, because they have the identical instances.

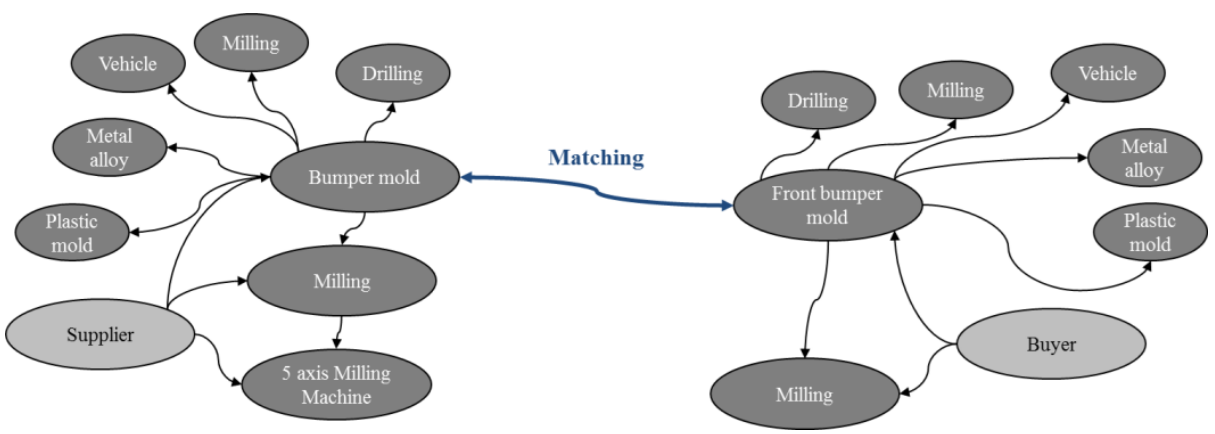

Fig. 6. Concept diagram for semantic matching: the buyer's product requirements and the supplier's manufacturing capability

Fig. 7 presents an exemplary concept diagram about how to match buyer's supplier requirements with supplier's non-manufacturing capability information. For example, a buyer wants to work with a 'global company.' This requirement is explicated as shown in Table 1: A supplier can be interacted in English, has overseas branch offices, has transaction experiences with foreign buyers, and can deliver products abroad. 
Subsequently, buyer's supplier requirements are matched with the supplier's non-manufacturing capability. In this framework, the supplier instance is matched with the global company instance in the buyer ontology, because they have instances which have identical properties.

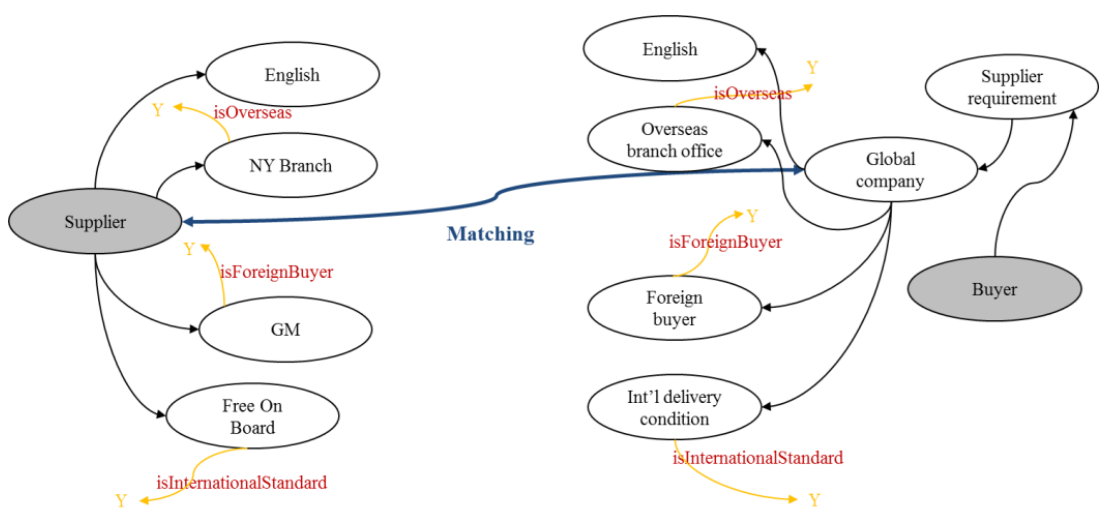

Fig. 7. Concept diagram for sematic matching: the buyer's supplier requirement and the supplier's non-manufacturing capability

\section{Prototype}

Most existing ontology-based systems have often been hindered by the slow reasoning speed of reasoning engines. Therefore, we have implemented a prototype to test feasibility. Ontology is built with Protégé, reasoning is automated with Pro-Reasoner, and semantic matching is performed with SPARQL.

Experiment is carefully conducted to measure the computational time of reasoning and matching by changing the number of suppliers. The results are shown in Table 2. Since suppliers are usually registered in the framework, the framework always has adequate time to execute reasoning on supplier's potential capability. Therefore, the reasoning time may be regarded as sufficiently fast. On the other hand, semantic matching of buyer's requirements with supplier's capability information is executed within a second. It proves the framework can be widely used in practice.

Table 2. Computational time of reasoning and matching

\begin{tabular}{|c|c|c|}
\hline \# of suppliers & Reasoning time $(\mathrm{sec})$ & Matching time $(\mathrm{sec})$ \\
\hline 100 & 38.39 & $<0.1$ \\
\hline 200 & 51.82 & $<0.1$ \\
\hline 600 & 84.12 & $<0.1$ \\
\hline 1,000 & 101.12 & $<0.1$ \\
\hline
\end{tabular}




\section{Conclusion}

The proposed semantic-web based supplier discovery framework includes ontology building, reasoning and semantic matching. 1) A key ontology is developed to represent the buyer's requirements and the supplier's capability information. 2) Supplier's potential capability based on the input data is reasoned, since suppliers may not be fully aware of the buyer's requirements that they can potentially satisfy. 3) Buyer's requirements are semantically matched with supplier's capability information.

Up until now, supplier discovery methods have only focused on matching product requirements with the supplier's manufacturing capability at a semantic level. As the proposed framework extends to consider supplier requirements as well as product requirements, the framework facilitates the building of a long-term strategic supply chain. Also, sustainable supply chain can be built since qualified suppliers are discovered strategically.

Finally, we have implemented a prototype of the framework to test feasibility. It proves the framework can be widely used in practice. In future work, to reflect industry realities, we will extend the ontology by capturing the supplier's capability information systematically.

\section{References}

1. Goffin, K., Szwejczewski, M., New, C.: Managing suppliers: when fewer can mean more. International Journal of Physical Distribution \& Logistics Management 27(7), 422-436 (1997)

2. Ameri, F., Dutta, D.: A Matchmaking Methodology for Supply Chain Deployment in Distributed Manufacturing Environments. Journal of Computing and Information Science in Engineering 8(1), 1-9 (2008)

3. Cai, M., Zhang, W.Y., Chen, G., Zhang, K., Li, S.T.: SWMRD: a Semantic Web-based manufacturing resource discovery system for cross-enterprise collaboration. International Journal of Production Research 48(12), 3445-3460 (2010)

4. Jang, J., Jeong, B., Kulvatunyou, B., Chang, J., Cho, H.: Discovering and integrating distributed manufacturing services with semantic manufacturing capability profiles. International Journal of Computer Integrated Manufacturing 21(6), 631-646 (2008)

5. Kulvatunyou, B.S., Cho, H., Son, Y.J.: A semantic web service framework to support intelligent distributed manufacturing. International Journal of Knowledge-based and Intelligent Engineering Systems 9(2), 107-127 (2005)

6. Virolainen, V.: A survey of procurement strategy development in industrial companies. International Journal of Production Economics 56-57(1), 677-688 (1998)

7. McGuinness, D., Van Harmelen, F.: OWL web ontology language overview. W3C Recommendation, 1-22 (2004)

8. Dickson, G.W.: An analysis of vendor selection systems and decisions. Journal of Purchasing 2(1), 5-17 (1966)

9. Thanaraksakul, W., Phruksaphanrat, B.: Supplier evaluation framework based on balanced scorecard with integrated corporate social responsibility perspective. In: Proceedings of the International MultiConference of Engineers and Computer Scientists, vol. 2, pp. 5-10 (2009) 